\title{
JURISPRUDENCIA AMBIENTAL EN CASTILLA Y LEÓN \\ (PRIMER SEMESTRE 2017)
}

\author{
IÑIGO SANZ RUBIALES \\ Catedrático de Derecho Administrativo \\ Universidad de Valladolid \\ isanz@der.uva.es
}

\begin{abstract}
SUMARIO: 1. Supuestos de inaplicación justificada de evaluación de impacto ambiental. 1.1. La evaluación de impacto no se aplica a modificaciones no sustanciales de proyectos existentes. 1.2. Incidencia en la red Natura y evaluación de impacto: principio de proporcionalidad. 2. Reclamaciones de responsabilidad patrimonial por daños derivados de ataques de especies protegidas (lobos). 3. Espectáculos taurinos y protección de animales: sobre el toro enmaromado de Astudillo. 4. La dinámica de las aguas: los arroyos también pueden desaparecer.
\end{abstract}

\section{SUPUESTOS DE INAPLICACIÓN JUSTIFICADA DE EVALUACIÓN DE IMPACTO AMBIENTAL}

1.1. La evaluación de impacto no se aplica a modificaciones no sustanciales de proyectos existentes

La STSJ de Castilla y León (Sala de lo Contencioso-Administrativo, Valladolid) de 24 de enero de 2017 resuelve el recurso interpuesto por Ecologistas en Acción contra la Orden de la Consejería de Fomento y Medio Ambiente de la Junta de Castilla y León de 29 de mayo de 2014, publicada en el Boletín Oficial de Castilla y León de 13 de junio de 2014, por la que se concede, en los términos que en ella se indican, autorización ambiental para una instalación de molienda y expedición de cemento ubicada en el término municipal de La Parrilla (Valladolid). El motivo de la impugnación es no haber sometido la actividad referida a evaluación de impacto ambiental (EIA), la cual, a juicio de la demandante, es necesaria a tenor de lo dispuesto en el anexo III i), "Fábricas de cemento", de la Ley 11/2003, de 8 de abril, de Prevención Ambiental de Castilla y León, al que se remite su artículo 45 , y de lo establecido en el anexo I, Grupo 4 i), del Real Decreto Legislativo 1/2008, de 11 de enero, por el que se aprueba el texto refundido de la Ley de Evaluación de Impacto Ambiental de proyectos, al que se remite su artículo 3.1, que exige dicha evaluación en las 
"Instalaciones para la fabricación de cemento o de clinker en hornos rotatorios, con una capacidad superior a 500 toneladas diarias, o de clinker en hornos de otro tipo, con una capacidad superior a 50 toneladas al día. Instalaciones dedicadas a la fabricación de cal en hornos rotatorios, con una capacidad superior a 50 toneladas por día”.

Sin embargo, de las pruebas presentadas se deduce que la actividad que se desarrolla en las instalaciones litigiosas no es una actividad de fabricación de clinker y/o cemento en horno (FD $3 .^{\circ}$ ). En efecto, la actividad que se realiza no consiste en fabricar cemento, como si de una cementera se tratara, sino que, a partir del cemento fabricado, se lleva a cabo la molienda de clinker (cemento en bruto) y se añaden sustancias diversas para el producto final. Con esto bastaría para entender no exigible la evaluación de impacto ambiental. "En la actividad a la que se refiere la Orden impugnada no se utiliza horno" (FD $5 . .^{\circ}$ ), con lo que no resulta de aplicación la previsión de la legislación de impacto ambiental (cfr. artículo 3 y anexo I del RD Legislativo 1/2008).

Pero hay que añadir otro argumento (FD 4. ${ }^{\circ}$ ): "[...] esta evaluación solo será necesaria si así viene exigido por la legislación aplicable, lo que aquí no sucede teniendo en cuenta que se trata de una instalación existente que no se modifica -y menos con carácter sustancial- con la Orden impugnada". Y el Tribunal menciona la recentísima Sentencia de 14 de diciembre de 2016 (casación 3773/2015), que desestimó el recurso de casación interpuesto por la Federación Ecologistas en Acción de Castilla y León contra la Sentencia de la Sala del mismo Tribunal Superior de Justicia de Castilla y León de 27 de octubre de 2015. Por eso, concluye la Sala: "Las evaluaciones de impacto ambiental, pues, se exigen a las nuevas instalaciones o a las que son objeto de modificación sustancial, pero no a las instalaciones existentes, pues éstas ya están efectivamente implantadas".

Esta doctrina, muy ceñida a la letra de la Ley, se ha asentado claramente por las numerosas sentencias que en los últimos meses (años 2016 y 2017) vienen confirmando la excepción de sometimiento a EIA de la mera modificación no sustancial de instalaciones existentes, de acuerdo con el principio de proporcionalidad. 


\subsection{INCIDENCIA EN LA RED NATURA Y EVALUACIÓN DE IMPACTO: PRINCIPIO DE PROPORCIONALIDAD}

La STSJ (Sala de lo Contencioso-Administrativo, Burgos) de 20 de enero de 2017 resuelve un recurso de apelación interpuesto por dos particulares contra la sentencia del Juzgado Contencioso-Administrativo de Soria que confirmó la legalidad del Proyecto de Obras para "Mejora y puesta en servicio del Camino de San Juan", aprobado por Acuerdo del Pleno del Ayuntamiento de Villar del Ala de 29 de diciembre de 2014.

Entre otros motivos que alegan los recurrentes, está el de que dicha obra debería haberse sometido a evaluación de impacto ambiental de acuerdo con el artículo 45 de la Ley 42/2007, de 13 de diciembre, del Patrimonio Natural y de la Biodiversidad, cuyo párrafo $4 .^{\circ}$ (referido a las zonas especiales de conservación y a las zonas de especial protección de aves) establece:

4. Cualquier plan, programa o proyecto que, sin tener relación directa con la gestión del lugar o sin ser necesario para la misma, pueda afectar de forma apreciable a los citados lugares, ya sea individualmente o en combinación con otros planes o proyectos, se someterá a una adecuada evaluación de sus repercusiones en el lugar, que se realizará de acuerdo con las normas que sean de aplicación, de acuerdo con lo establecido en la legislación básica estatal y en las normas adicionales de protección dictadas por las Comunidades autónomas, teniendo en cuenta los objetivos de conservación de dicho lugar.

Pues bien, la Sala realiza un análisis exhaustivo de la documentación obrante en el expediente para determinar que, efectivamente, la obra aprobada no afecta de forma apreciable a dichos lugares: "Parece desprenderse de los informes que se aportan por la parte, que no del IRNA, que una parte muy pequeña del camino discurre por zona ZEPA, afectando a $105,40 \mathrm{~m}^{2}$, pero como bien dice el núm. 4 de este artículo 45 que hemos trascrito, es preciso que el proyecto pueda afectar de forma apreciable a los citados lugares, lo cual no parece factible teniendo en cuenta la muy pequeña superficie afectada y teniendo en cuenta que ya parte de esta superficie lo constituye el camino existente". Además, "cabe señalar que ninguno de estos hábitats se considera 
como prioritarios, ni ninguna de estas especies son especies prioritarias, según se desprende por lo recogido en estos Anexos de esta Ley 4/2007".

Además, el trazado del camino al que responde el proyecto discurre en parte dentro de la ZEPA Sierra de Urbión, aunque no abarca terrenos del LIC Sierras de Urbión y Cebollera (FD 12.ำ) .

Y concluye:

Por lo que se refiere a la flora y fauna que pueda afectar este camino y la obra en él prevista por el proyecto impugnado, no cabe la menor duda de que este camino presenta una riqueza natural, pero no se aprecia, a pesar de lo que indica el perito judicial, que esta riqueza natural sea de la suficiente entidad como para que proceda anular la resolución impugnada y someter el proyecto, con relación a la obra por él prevista, a una evaluación medioambiental, fuera del informe ya realizado por los técnicos de la Junta de Castilla León.

Y para corroborar la proporcionalidad de la medida adoptada por la Junta, afirma con contundencia la inexistencia de los supuestos de aplicación de la evaluación de proyectos o de la evaluación ambiental estratégica regulada en la Ley 21/2013:

El Proyecto impugnado no se encuentra en ninguno de los supuestos en que exija evaluación ambiental estratégica, por cuanto que no se comprende dentro de los supuestos recogidos en el artículo 6 de la anteriormente indicada Ley 21/2013; tampoco se comprende dentro de la aplicación de la evaluación de impacto ambiental, a que se refiere el artículo 7 de la misma Ley, por cuanto que no se comprende en ninguno de los supuestos que recoge dicho precepto.

[...] Por otra parte, conforme al artículo 46.4 de dicha Ley, procedería someter el proyecto a una adecuada evaluación de sus repercusiones en el espacio cuando pueda afectar de forma apreciable a las especies o hábitats de los citados espacios, pero no ha considerado esta circunstancia la autoridad competente medioambiental, y la normativa aplicable no lo exige, como hemos visto respecto de la normativa básica del Estado y conforme a lo que previene la actualmente vigente normativa autonómica que se recoge en el Decreto legislativo 1/2015, de 12 de noviembre, por el que se aprueba el texto refundido de la Ley de Prevención Ambiental de 
Castilla y León, pues en su artículo 49 establece los proyectos que deban someterse a evaluación de impacto ambiental.

En definitiva, aunque literalmente pueda haber indicios de exigibilidad de sometimiento a evaluación de impacto ambiental, la escasa trascendencia del camino, la menor aún de la obra de reforma, la constatación realizada por los órganos con competencias ambientales sobre el alcance de dicha actuación y la preparación técnica de estos llevan a confirmar la no necesidad de dicha evaluación de acuerdo con el principio de proporcionalidad.

\section{RECLAMACIONES DE RESPONSABILIDAD PATRIMONIAL POR DAÑOS DERIVADOS DE ATAQUES DE ESPECIES PROTEGIDAS (LOBOS)}

La STSJ de Castilla y León (Sala de lo Contencioso-Administrativo, Burgos) de 13 de febrero de 2017 viene a resolver un recurso contra la desestimación por silencio administrativo de una reclamación de responsabilidad patrimonial por los daños producidos en el ganado de una finca del recurrente en El Espinar (Segovia). La sentencia, por sí misma, pone de manifiesto la expansión de los asentamientos del canis lupus al sur del Duero (donde es especie estrictamente protegida) y, a la vez, el resurgimiento del inmemorial conflicto entre los ganaderos y el lobo.

Frente a la solicitud de una indemnización de más de 30.000 euros, la Administración demandada acepta la relación de causalidad y el título de imputación ejercitado, pero se opone, no obstante, a la reclamación por entender injustificadas las cuantías reclamadas por los diferentes conceptos indemnizables. Sostiene que el perjuicio causado es el correspondiente al daño emergente y lucro cesante de los animales que perdió, y ese valor no es otro que el identificado razonada e individualizadamente en el informe del Servicio de Espacios Naturales. La Sala, ante este reconocimiento de la Administración autonómica del daño y de la relación de causalidad, declara la responsabilidad de la Administración y pasa a determinar la cuantía indemnizatoria, que es lo realmente problemático (FD $3 . \stackrel{\circ}{)}$ ).

La cuantía solicitada por el reclamante se apoya en un informe de un perito que tiene en cuenta no solo la cuantificación reglada, sino otros daños derivados de 
la presencia de los lobos. En efecto, de la fase de prueba se deduce -y así lo reconocen los dos peritos - la realidad de los daños reclamados, así como la diligencia del titular de la explotación en la adopción de diversas medidas con el fin de evitar los ataques, tales como agrupar el ganado en cercas más pequeñas para nodrizas con el fin de que se defiendan como grupo, carros para proteger el ganado, etc., habiendo comprado incluso burros para espantar a los lobos.

Por otro lado, ambos peritos coinciden también en que la tasa de fecundidad de El Carmocho está por debajo de la media para este tipo de explotaciones como consecuencia de la presencia de lobos, y que ha disminuido mucho la paridera.

Este no es un fenómeno desconocido por los ganaderos: la producción de leche y la reproducción del ganado se ven afectadas por el estrés o ansiedad derivada de la presencia de lobos. Si esta es habitual, la productividad se reduce aún más.

Por otro lado, el agente medioambiental, testigo cualificado, puso de manifiesto que efectivamente hay una población permanente y estable de siete lobos, que se alimentan de especies silvestres y de ganado doméstico. Según este testigo, "el procedimiento de control actual, órdenes de eliminación periódicas, no es mecanismo suficiente para acabar con los daños que causan los lobos, los daños van en aumento y a los Agentes no se les permite adoptar mayores medidas de control al respecto". Además, afirma, "la explotación ganadera de la recurrente no puede hacer nada en relación con los lobos, está bien gestionada [...], colabora con el Agente Medioambiental cuando es requerida para ello, y adopta medidas como retirar los terneros recién nacidos de las zonas donde hay más tránsito de lobos, efectúa movimientos de ganado para evitar los ataques del lobo, moviéndolos por distintos cuarteles de pastos, afirmando que el campeo de los lobos causa inquietudes al ganado, y por tal circunstancia cree que el acoso de los lobos afecta a la paridera". Es más, el testigo afirmó que en los dos últimos años no había recibido ninguna orden de eliminación y que los medios personales y materiales son a todas luces insuficientes. Y a preguntas de la ponente manifestó que "por parte de la Junta de Castilla y León se había autorizado el radio-marcaje a los lobos de la zona que él mismo controla, pero que curiosamente su Jefa de Patrulla dio orden de 
retirar el radio-marcaje, reconociendo que estos ataques de lobos están produciendo daños a la explotación ganadera".

Ante tan abrumadora suma de argumentos, la Sala entiende correcta la metodología de cálculo de los daños usada por el reclamante y confirma la indemnización solicitada. Son, por una parte, la extraordinaria diligencia del titular de la explotación (y su correspondiente ausencia en la actuación administrativa) y, por otra, los efectos secundarios sobre la salud y reproducción del ganado los que determinan que la indemnización no se limite a los pagos compensatorios establecidos en las órdenes correspondientes, sino que alcance a resarcir todos los daños efectivamente producidos y susceptibles de valoración económica.

\section{ESPECTÁCULOS TAURINOS Y PROTECCIÓN DE ANIMALES: SOBRE EL TORO ENMAROMADO DE ASTUDILLO}

La STSJ (Sala de lo Contencioso-Administrativo, Valladolid) de 2 de noviembre de 2016 resuelve el recurso planteado por la Asociación Nacional para la Protección y el Bienestar de los Animales (ANPBA) contra la Orden FYM/751/2014, de 31 de julio, por la que se declara como espectáculo taurino tradicional, al festejo taurino denominado "Toro enmaromado de Astudillo/Toro del pueblo".

Según la demandante, el espectáculo "toro enmaromado" "es contrario al Decreto 14/1999, de 8 de enero por el que se aprueba el Reglamento de Espectáculos Taurinos Populares de la Comunidad de Castilla y León en cuanto en su desarrollo se infringe maltrato al animal, y por tanto es contrario al principio general que preside dicha norma de ausencia de maltrato a las reses de lidia (art. 2 b)". Además, la documentación obrante en el expediente "no acredita el requisito esencial previsto en el artículo 28 de que 'se venga realizando en la localidad de forma continuada desde tiempos inmemoriales, desarrollándose de acuerdo con la costumbre del lugar'”. En efecto, no existen documentos históricos que demuestren fehacientemente la antigüedad exigida de dicho espectáculo, que es conditio sine qua non para su reconocimiento excepcional según el artículo 29.2 c) del Decreto 14/1999. 
En efecto, tal y como recuerda el FD $4 .^{\circ}$ de la sentencia, según el citado Decreto, se prohíbe en todos los espectáculos taurinos tradicionales y con carácter general "herir, pinchar, golpear, sujetar o tratar de cualquier otro modo cruel a las reses" (art. 19.1). Pero esta prohibición general tiene una excepción: se refiere a las actuaciones que "excepcionalmente, sean inherentes a la celebración de un espectáculo taurino tradicional". Ahora bien, para que un espectáculo pueda ser declarado "tradicional" según el Decreto tiene que ser "inmemorial", concepto jurídico que la norma reglamentaria concreta en doscientos años. Por lo tanto, únicamente cabrá celebrar el espectáculo del toro enmaromado (que implica que la res va sujeta mediante una maroma) si se demuestra su celebración, al menos, durante los dos siglos precedentes. Merece la pena destacar que, tal y como recuerda la propia sentencia (FD 5.๑), solo tres localidades de la región han obtenido la calificación de "inmemorial" del correspondiente festejo del toro enmaromado (a efectos de exceptuar la prohibición de trato cruel), lo que evidencia que este tipo de espectáculo taurino no es tan tradicional.

En el expediente de declaración y en la resolución del previo recurso de reposición, la demandada aporta datos históricos sobre espectáculos taurinos en el pueblo de Astudillo y se remonta al 1565, añadiendo otras menciones de $1740,1751,1773,1786$, etc. Pero — señala la sentencia - "como vemos, todos estos antecedentes aluden a funciones de toros o novillos en general sin especificar ninguna de las especiales características con las que se pretende obtener la declaración de festejo tradicional, y más concretamente nada se dice sobre el enmaromamiento de la res, que es lo más característico del festejo, y que precisamente es lo que justifica la declaración solicitada ya que el art. 19, como vimos, prohíbe, en los espectáculos taurinos populares 'sujetar"' (FD 4.ํ). Y continúa: "Esta falta de prueba tampoco puede verse suplida por las declaraciones testificales, dada la antigüedad requerida por la norma" (FD $5 . \stackrel{\circ}{\circ}$ ).

Por todo ello, la sentencia declara la nulidad de la Orden FYM/751/2014, de 31 de julio, por la que se declara como espectáculo taurino tradicional, al festejo taurino denominado "Toro enmaromado de Astudillo/Toro del pueblo", así como la revocación de la inscripción de dicho espectáculo en el Registro de Espectáculos Taurinos Tradicionales de la Comunidad de Castila y León. 


\section{LA DINÁMICA DE LAS AGUAS: LOS ARROYOS TAMBIÉN PUEDEN DESAPARECER}

La STSJ de 12 de enero de 2017 (Sala de lo Contencioso-Administrativo, Valladolid) resuelve el recurso contra una multa impuesta por el presidente de la Confederación Hidrográfica del Duero de 1.800 euros por la "ocupación y eliminación del cauce de un brazo del Arroyo del Portillo en un tramo de 280 metros de longitud, mediante el tapado del mismo, empleando para ello unos $560 \mathrm{~m}^{3}$ de tierras" (en el término municipal de Villamayor de Campos, Zamora).

Debido a la escasa cuantía y entidad de la sanción, sorprende que se interponga el recurso. Pero, como veremos con posterioridad, "es más el fuero que el huevo", porque lo que plantea el recurrente es que dicho brazo del arroyo no existe, lo que provocaría la inexistencia - por falta de supuesto de hecho- de la infracción denunciada. De hecho, como justifica la Sala en su FD 2. ${ }^{\circ}$, "el único punto controvertido en el caso es el de si existía o no el arroyo que defiende la Administración —el actor ha admitido en todo momento que procedió al relleno y tapado de una zona 'húmeda' que dice que había sido realizada por los anteriores propietarios y llega a mantener en su demanda que la controversia de fondo es exclusivamente técnica, limitada a la determinación de la existencia o inexistencia del arroyo, de manera que si en la realidad existiese es evidente que su recurso debería decaer-" (por la redacción se aprecia que el sancionado está muy seguro de la licitud de su acción, hasta el punto de reconocer su potencial naturaleza infractora si existiese tal arroyo).

La Sala (FD 3.) parte de la base del principio in dubio pro reo porque estamos en el ámbito de la potestad sancionadora, y resuelve que "en el supuesto de autos no ha quedado probada suficientemente la existencia del arroyo cuyo tapado determina la falta leve apreciada, conclusión que se fundamenta, uno, en el informe pericial [...] acompañado con la demanda [...]; dos, en el informe del Área de Estructuras Agrarias del Servicio de Agricultura y Ganadería de la Delegación Territorial de Zamora de la Junta de Castilla y León remitido en el periodo de prueba, en el que se pone de relieve que no consta en el expediente de concentración parcelaria que hubiera ningún arroyo, ni brazo del mismo". Termina reconociendo que "la ratio decidendi de esta sentencia es que no se 
ha probado la existencia del brazo del cauce y no que se ha acreditado su inexistencia", y ello, sin perjuicio de que lo documente el mapa topográfico 1:25000 del Instituto Geográfico Nacional.

En definitiva, si los cursos de agua "mayores" se muestran estables y difícilmente alterables, los cursos pequeños, sobre todo brazos de arroyos, pueden, con el paso del tiempo y la actividad humana, verse fácilmente modificados. Es por eso conveniente que la Administración actualice constantemente sus planos e inspeccione los elementos integrantes de las zonas de policía y, sobre todo, del dominio público hidráulico para evitar la degradación de este. 